\title{
Satisfação e insatisfação no trabalho de profissionais em Educação Física que atuam em academias de ginástica
}

\author{
Job satisfaction and dissatisfaction of physical education professionals who work in gyms \\ Satisfacción e insatisfacción laboral de profesionales en educación física que laboran en \\ gimnasios
}

Caroline Broch $^{a}$ (D) , Ana Flávia Backes ${ }^{b *}$ (D) , Rosemeire Gonçalves Lopes ${ }^{a}$ (D), Ana Caroline Farias Fioria ${ }^{\mathbb{D}}$, Fabiane Castilho Teixeira Breschiliare ${ }^{\mathrm{C}}$ (D)

Palavras-chave:

Satisfação no

trabalho;

Profissional;

Educação física;

Academias de

ginástica.

\begin{abstract}
RESUMO
O estudo qualitativo investigou a satisfação e a insatisfação no trabalho de dez profissionais de Educação Física que atuam em academias de ginástica no município de Maringá-PR. Empregou-se uma entrevista semiestruturada e a análise de conteúdo para o tratamento dos dados. Os resultados revelaram que os profissionais de Educação Física estavam insatisfeitos com a remuneração, com as condições de trabalho, com a relevância social da vida no trabalho e com a articulação entre trabalho e espaço total de vida; e estavam satisfeitos com a integração no trabalho e com as oportunidades de progressão na carreira. Conclui-se que há uma relação direta entre as condições objetivas de trabalho e a satisfação e a insatisfação com o desempenho profissional no contexto de atuação das academias de ginástica.
\end{abstract}

Keywords: Job satisfaction; Professional; Physical education; Gyms.

\begin{abstract}
The qualitative study was to investigate job satisfaction and dissatisfaction of the ten Physical Education professionals who work in gyms in the Maringá-PR. A semi-structured interview and Content Analysis were used to process the data. The results revealed that the Physical Education professionals were dissatisfied with the remuneration, working conditions, social relevance of the work and the articulation between work and the total space of life; and were satisfied with job integration and career advancement opportunities. It is concluded that there is a direct relationship between objective working conditions and satisfaction and dissatisfaction with professional performance in the context of performance of gyms.
\end{abstract}

\section{RESUMEN}

El estudio cualitativo investigó la satisfacción e insatisfacción laboral de diez profesionales de Educación Física que laboran en gimnasios en Maringá-PR. Se utilizó una entrevista semiestructurada y Análisis de Contenido. Los resultados revelaron que los profesionales de Educación Física estaban insatisfechos con la remuneración, las condiciones laborales, la relevancia social del trabajo y articulación entre el trabajo y espacio total de la vida; y estaban satisfechos con la integración laboral y las oportunidades de promoción profesional. Se concluye que existe una relación directa entre las condiciones objetivas de trabajo y la satisfacción e insatisfacción con el desempeño profesional en el contexto del desempeño de los gimnasios.

${ }^{a}$ Centro Universitário de Maringá - Unicesumar. Maringá, PR, Brasil.

bUniversidade Federal de Santa Catarina - UFSC, Centro de Desportos, Programa de Pós-graduação em Educação Física. Florianópolis, SC, Brasil.

'Universidade Federal de Santa Catarina - UFSC, Centro de Desportos. Florianópolis, SC, Brasil.

\author{
*Autor correspondente: \\ Ana Flávia Backes \\ E-mail: anafbackes@hotmail.com
}




\section{INTRODUÇÃO}

A notoriedade que a Educação Física vem ganhando na sociedade brasileira apresenta relação com o fortalecimento do campo acadêmico-científico, que trouxe novas conformações para o desenvolvimento da área (Lazzarotti et al., 2012). Paralelamente a esse processo, e sofrendo seus impactos, desencadeou-se a ampliação de seus espaços de atuação profissional. A expansão da mercantilização das práticas esportivas e o consumo de seus bens e serviços (Proni, 2010), e também a expressiva valorização das práticas corporais como condição de saúde e estética (Furtado e Santiago, 2015), trouxeram como contrapartida expectativas mais amplas do mercado de trabalho para os profissionais de Educação Física (Proni, 2010).

Se, por um lado, houve um incremento das possibilidades de inserção no mercado de trabalho pelos profissionais da área, é notório, por outro, que as mudanças sofridas pelo contexto profissional nas últimas décadas, em maior ou menor grau de intensidade, afetaram as relações de trabalho socialmente instituídas (Verenguer, 2004). Observam-se, portanto, impactos diretos na satisfação dos profissionais que atuam em academias de ginástica.

A expansão da atuação em Educação Física já foi destacada em discussões acadêmicas e tem sido percebida pela sociedade como um todo. Além da representativa inserção dos profissionais da área em academias de ginástica, conforme evidenciado por Furtado e Santiago (2015), é possível verificar sua vinculação a clubes, clínicas de reabilitação, hotéis, empresas que prestam serviços de atividades físicas e esportivas e escolinhas de iniciação esportiva, com destaque para o campo fitness, que cresceu consideravelmente quanto à oferta de trabalho e inserção profissional (Proni, 2010).

Neste ínterim, observa-se o debate acadêmico em torno da temática sobre a satisfação no trabalho. No entanto, um mapeamento na literatura evidenciou que, na área de Educação Física, essa discussão ainda é incipiente. A satisfação e a insatisfação profissional na área têm sido abordadas principalmente no âmbito escolar (Both, 2011; Farias et al., 2015; Nascimento et al., 2019) e no ensino superior (Broch, 2018; Silva et al., 2010). Esses estudos, entre outras questões, destacam as relações existentes entre a satisfação e o desempenho profissional.

Por isso, a problemática acerca da satisfação no trabalho de profissionais de Educação Física que atuam em academias de ginástica requer um maior empreendimento dos pesquisadores. Um estudo que tomou esse tema como foco destacou que a insatisfação está relacionada à remuneração, enquanto a satisfação foi atribuída ao reconhecimento por parte dos alunos, ao entrosamento com a equipe e às condições de trabalho e imagem profissional (Mendes e Azevêdo, 2014). De forma similar, evidências mostram que a satisfação com a profissão declarada por profissionais da área, inseridos em espaços informais de atuação, não está associada à remuneração, sendo considerada uma adversidade nesse âmbito de trabalho (Antunes et al., 2017; Freitas et al., 2014). Com base nesse diagnóstico e tomando a realidade do município de Maringá-PR, o estudo delimitou-se a investigar a satisfação e a insatisfação no trabalho de dez profissionais de Educação Física que atuam em academias de ginástica.

\section{METODOLOGIA}

A presente pesquisa caracteriza-se como qualitativa e descritiva (Gil, 2017). Os participantes foram selecionados por conveniência, conforme os seguintes critérios: a) ser formado, no mínimo, há um ano em Educação Física - bacharelado; b) atuar, no mínimo, há um ano em academias de ginástica; c) concordar com os termos da pesquisa. Participaram da pesquisa dez (10) profissionais de Educação Física que atuam em academias de ginástica em Maringá-PR $(M=6 ; F=4)$, com faixa etária média de 29 anos e tempo de atuação médio de 3,5 anos (Tabela 1). A maior parte dos profissionais era pósgraduada (60\%) e atuava em mais de um local e espaço (60\%), distribuindo-se principalmente nos contextos de saúde e esporte. Para garantir anonimato, os profissionais foram apresentados por códigos, a saber: P1, P2, P3, P4, P5, P6, P7, P8, P9 e P10.

$\mathrm{Na}$ coleta de dados, empregou-se uma entrevista semiestruturada a partir de um roteiro contendo 12 questões, com foco nas dimensões: perfil do entrevistado; características do exercício profissional; condições de trabalho; satisfação e insatisfação com a profissão; expectativas com a atuação profissional. Para a elaboração do instrumento, organizou-se uma matriz analítica com base no referencial teórico consultado para o estudo (Broch, 2018; Guimarães et al., 2011), validada por três professores doutores da área. As entrevistas foram realizadas individualmente, mediante a disponibilidade dos participantes da pesquisa, em ambiente adequado, livre de interferência sonora.

Para a recolha dos dados, utilizou-se um gravador de voz de um aparelho celular. $\mathrm{O}$ tempo médio de duração das entrevistas foi de 15 minutos. Após a transcrição, as entrevistas foram encaminhadas aos participantes para confirmar a veracidade dos dados. O Termo de Consentimento Livre e Esclarecido (TCLE) foi assinado por todos. A pesquisa foi aprovada pelo Comitê Permanente de Ética e Pesquisa envolvendo Seres Humanos do Centro Universitário de Maringá - Unicesumar, sob o parecer $\mathrm{n}$. 3.524.282/2019.

Os dados foram tratados com base na Análise de Conteúdo, proposta por Bardin (2016), uma técnica que analisa a informação das comunicações e emprega procedimentos sistemáticos na leitura de dados. As categorias de análise foram elaboradas, a priori, por procedimento dedutivo. $\mathrm{O}$ processo compreendeu três etapas: 1) Pré-análise, relativa à seleção e organização 
Tabela 1. Perfil dos profissionais.

\begin{tabular}{|c|c|c|c|c|c|c|}
\hline Profissionais & Sexo & Idade & Formação & $\begin{array}{c}\text { Tempo de } \\
\text { Atuação }\end{array}$ & $\begin{array}{l}\text { Local de } \\
\text { Atuação }\end{array}$ & Área de Atuação \\
\hline P1 & M & 29 & Mestrado & 3 anos & Academia & Musculação \\
\hline $\mathrm{P} 2$ & $\mathrm{~F}$ & 29 & Graduação & 2 anos & Academia & Musculação, Funcional, Dança \\
\hline P3 & $\mathrm{F}$ & 24 & Graduação & 2 anos & Academia & Musculação, Funcional e Lutas \\
\hline P4 & $\mathrm{F}$ & 25 & Graduação & 4 anos & Academia & Natação e Hidroginástica \\
\hline P5 & M & 28 & Graduação & 4 anos & $\begin{array}{l}\text { Academia e } \\
\text { Escola }\end{array}$ & Musculação e Ginástica \\
\hline P6 & M & 26 & Especialização & 3 anos & Academia & Musculação \\
\hline P7 & M & 43 & Graduação & 2 anos & Academia & Funcional \\
\hline P8 & M & 34 & Especialização & 3 anos & $\begin{array}{l}\text { Academia e } \\
\text { Escola }\end{array}$ & Treinamento Esportivo \\
\hline P9 & $M$ & 27 & Especialização & 7 anos & $\begin{array}{l}\text { Academia e } \\
\text { Laboratório }\end{array}$ & $\begin{array}{l}\text { Musculação, Gestão e Análise de } \\
\text { Movimento }\end{array}$ \\
\hline P10 & $\mathrm{F}$ & 26 & Especialização & 5 anos & $\begin{array}{l}\text { Academia e } \\
\text { Eventos }\end{array}$ & Funcional, Dança e Recreação \\
\hline
\end{tabular}

Legenda: $\mathrm{M}$ = Masculino; $\mathrm{F}=$ Feminino. Fonte: Elaborada pelas autoras (2021).

das informações contidas nas transcrições; 2) Exploração do material, referente à classificação do conteúdo em unidades de significado; 3) Tratamento dos resultados, relacionado à organização das categorias a partir da frequência das unidades de significado. O software QRS NVivo 12.0 foi utilizado na análise dos dados.

\section{RESULTADOS E DISCUSSÃO}

Os resultados são apresentados em um Mapa Conceitual (Figura 1), elaborado com a ferramenta CmapTools. Na parte central, constam as categorias e subcategorias relativas à satisfação no trabalho que emergiram das declarações dos participantes e que foram classificadas de acordo com a proposta de Walton (1973), utilizando-se da nomenclatura sugerida por Both (2011). Na extremidade, as linhas tracejadas representam a frequência de satisfação e insatisfação profissional para cada categoria/subcategoria de análise.

\section{REMUNERAÇÃO}

Os profissionais entrevistados destacaram a remuneração como um fator interveniente da satisfação no trabalho (P1, P2, P3, P4, P5, P6, P7, P8, P9, P10). A maioria deles (P1, P2, P5, P6, P8, P9, P10) demonstrou insatisfação, especialmente quando se compara a função que desempenham com a carga horária de trabalho semanal, conforme argumentam Furtado e Santiago (2015). Um dos relatos aponta: "Para mim, remuneração, carga horária e valorização estão conectadas. Para mim, são negativas, porque eu ganho pouco, tenho uma carga horária elevada e não sou valorizado, gostaria de estar ganhando mais e trabalhando menos" (P6).

Adicionalmente, os profissionais relataram que a insatisfação com a remuneração está associada ao baixo salário nos espaços de atuação informal da Educação Física: "Eu gostaria de ganhar mais, mas, infelizmente, o nosso piso de trabalho é complicado, não depende só da academia, é uma cultura que o profissional de Educação Física tem de receber 10,12, 13, dependendo a hora-aula" (P5).

Essa insatisfação também se verificou em estudos realizados com outros profissionais que atuam no espaço informal (Freitas et al., 2014; Krug et al., 2009; Mendes e Azevêdo, 2014) e formal (Both et al., 2017; Farias et al., 2015; Nascimento et al., 2019). Os diagnósticos revelam, de modo geral, a baixa remuneração atribuída aos profissionais da área quando comparada à carga horária e função desempenhada, que não reflete, por vezes, uma compensação adequada para suprir as necessidades pessoais, sociais e econômicas (Both, 2011).

Dados verificados na literatura demonstram que os profissionais vinculados às áreas de fitness e esporte representam a categoria com a remuneração mais baixa (Fonseca e Souza, 2020). A remuneração precária, aliada ao desgaste físico e à longa jornada de trabalho, tem sido considerada uma das principais causas de insatisfação, desinvestimento e abandono dos profissionais que atuam em academias de ginástica com o avançar da idade (Antunes et al., 2017; Freitas et al., 2014; Palma et al., 2007), os quais migram para o ensino formal em busca de segurança e estabilidade financeira (Fonseca e Souza, 2020).

Por outro lado, alguns participantes (P3, P4, P7) relataram estar satisfeitos com a sua remuneração. Nesses casos, a percepção de satisfação foi motivada pela própria preparação profissional que possibilitou o reconhecimento do trabalho realizado e a obtenção de melhores gratificações. De acordo com P7: "Pelo que estou fazendo, pela carga horária e o tempo de hora-aula, sim, porque eu cobro um valor que acho justo. [...] dentro da profissão existem muitos profissionais, e quando estão bem preparados, requerem uma remuneração melhor". Esses resultados sugerem que a satisfação 


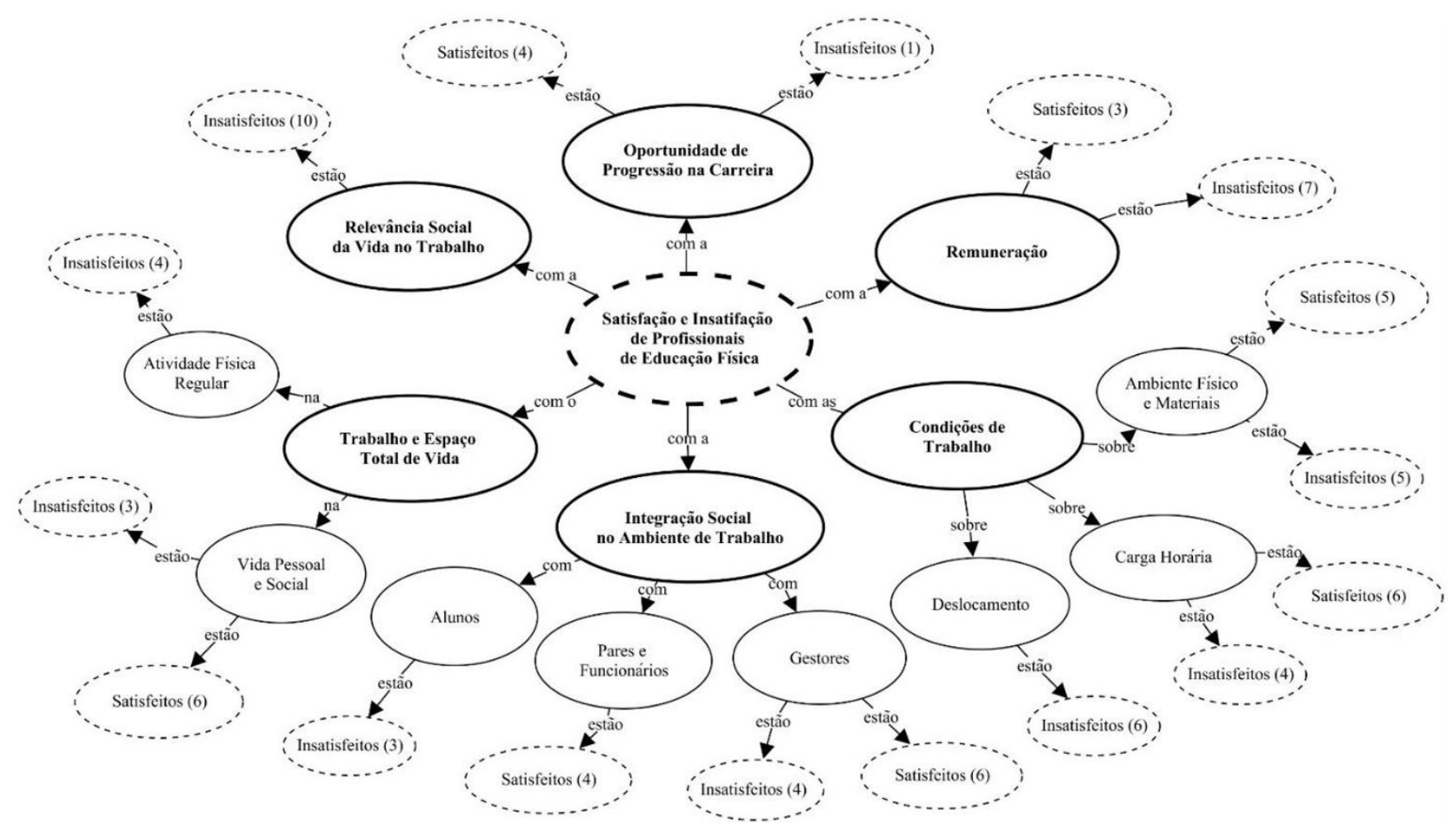

Figura 1. Satisfação e insatisfação no trabalho de profissionais de Educação Física. Fonte: Elaborada pelas autoras (2021).

com as condições salariais apresenta relação com a qualificação profissional. Embora não reflita a realidade evidenciada em estudos com profissionais que atuam no espaço informal (Freitas et al., 2014; Krug et al., 2009; Mendes e Azevêdo, 2014), maiores níveis de satisfação com a remuneração foram encontrados entre os que atuam em universidades (Broch, 2018), o que corrobora a indicação da relação com o investimento na formação e satisfação profissional.

\section{CONDIÇÕES DE TRABALHO}

$\mathrm{O}$ ambiente físico e os recursos materiais (P1, P2, $\mathrm{P} 3, \mathrm{P} 4, \mathrm{P} 5, \mathrm{P} 6, \mathrm{P} 7, \mathrm{P} 8, \mathrm{P} 9, \mathrm{P} 10)$, a carga horária (P1, P2, P3, P4, P5, P6, P7, P8, P9, P10) e o deslocamento (P2, P3, P4, P7, P8, P9) foram considerados fatores intervenientes na satisfação no trabalho. Com relação ao ambiente físico e a recursos materiais disponíveis nos locais de atuação, verificou-se uma percepção equilibrada entre os satisfeitos (P3, P5, P6, P7, P9) e insatisfeitos (P1, P2, P4, P8, P10). A adequada estrutura dos locais de trabalho interfere na satisfação profissional, por impactar nos resultados pretendidos, pois, segundo relata $\mathrm{P} 7$, " [...] uma parte positiva é a estrutura que me dão. [...] antes de fechar qualquer acordo eu deixo bem claro o que preciso para dar resultado". E P3 afirma que "[...] eu não encontro dificuldade, já que disponho do necessário para o desempenho do que faço, [...] o contratante já sabe da necessidade de ter uma estrutura adequada".
Por outro lado, a insatisfação profissional está ligada à falta de materiais e estrutura adequada para atender os alunos, conforme os relatos: "Alguns locais não têm estrutura adequada. Eles querem que você preste serviço bom, de qualidade, mas não têm os materiais necessários que deveriam ter para o atendimento" (P2). "Na minha sala não tem ventilação [...]. Tem um ventilador que fica parado, e quando tem muita gente na sala, não funciona" (P10).

Em relação à carga horária, uma parte considerável dos investigados parece estar satisfeita com o regime de trabalho semanal (P2, P3, P4, P5, P7, P9): "Hoje, eu coloquei que eu não trabalho mais no final de semana. Senão, a hora que a gente percebe, está trabalhando de segunda a segunda" (P2). Embora satisfeitos, alguns profissionais também mencionaram a possibilidade de ampliar a carga horária: "Sim, estou satisfeita com a carga horária. Tenho muitos horários ainda para completar, mas estou satisfeita" (P3).

Outro viés aponta que a insatisfação com a carga horária (P1, P6, P8, P10) está associada ao fato de os profissionais não conseguirem equilibrar o tempo com outras dimensões da vida pessoal, em função das horas que permanecem no ambiente de trabalho. P1 argumenta que "[...] a carga horária de trabalho, como eu disse anteriormente, eu gostaria de até diminuir um pouco, sair mais cedo, [...] até para melhorar minha parte pessoal", enquanto P8 afirma que "[...] não estou satisfeito com a minha carga horária, pois é muito intenso e se parar para pensar você acaba não tendo tempo para o lazer". 
As evidências mostram que a insatisfação dos profissionais da área com as condições de trabalho está relacionada, frequentemente, à falta de estrutura e equipamento, às longas jornadas de trabalho e ao acúmulo de maiores cargas horárias, tanto no ambiente informal (Antunes et al., 2017; Guimarães et al., 2011; Palma et al., 2007) quanto no ambiente formal de atuação (Both, 2011; Farias et al., 2015; Nascimento et al., 2019). A literatura também sugere que a insatisfação com as condições de trabalho se vincula diretamente ao tipo de trabalho desenvolvido, às pessoas atendidas, ao salário, à carga horária e às relações de trabalho estabelecidas (Furtado e Santiago, 2015).

Mendes e Azevêdo (2014) alertam que a realização pessoal e o prazer que os profissionais de Educação Física experimentam em suas atividades refletem, por vezes, na percepção de satisfação com as condições de trabalho. Isso pode justificar que, mesmo com uma carga horária média de aproximadamente 40 horas semanais, alguns profissionais manifestaram-se satisfeitos com essas condições no estudo realizado.

A insatisfação acerca das condições de trabalho também está relacionada ao tempo despendido no deslocamento (P2, P3, P4, P7, P8, P9), decorrente da variedade de locais de atuação. Esse tempo de deslocamento prejudica a qualidade do trabalho e impossibilita a dedicação a outros objetivos profissionais e pessoais, conforme atesta P2: "Minha maior dificuldade é a questão do deslocamento. [...] eu fico quatro horas no trânsito. Nesse tempo eu poderia estar rendendo, fazendo outra coisa [...]. Porque, no final das contas, você tá ali o tempo todo atrás de trabalho" e P3: "Sim, para nós profissionais da Educação Física que trabalhamos em vários locais é o deslocamento, pois você acaba perdendo um tempo que poderia estar aplicando uma aula".

O desgaste físico e emocional ocasionado pelo deslocamento entre os locais de atuação parece estar atrelado à condição de pluriemprego exercida por esses profissionais (Freitas et al., 2014). De fato, em função da baixa remuneração e da pouca estabilidade, se veem obrigados a acumular trabalhos em escolas, clubes ou diferentes academias de ginástica. De forma semelhante, o estudo de Guimarães et al. (2011) verificou que $84 \%$ dos que atuam em academias têm de dois a cinco empregos, enquanto Mendes e Azevêdo (2014) também constataram que mantinham, no mínimo, dois vínculos empregatícios $(81,1 \%)$, chegando a quatro em alguns casos $(9,4 \%)$, sempre motivados pela necessidade de ampliar a remuneração.

\section{INTEGRAÇÃO SOCIAL NO AMBIENTE DE TRABALHO}

Os participantes relataram que a satisfação no trabalho está ligada às relações interpessoais que estabelecem com os gestores (P1, P2, P3, P4, P5, P6, P7, $\mathrm{P} 8, \mathrm{P} 9, \mathrm{P} 10)$, com os pares e/ou demais funcionários ( $\mathrm{P} 3$, P4, P7, P9) e alunos (P2, P3, P8). A respeito das relações com os gestores, verificou-se que a maioria está satisfeita $(\mathrm{P} 1, \mathrm{P} 2, \mathrm{P} 4, \mathrm{P} 5, \mathrm{P} 7, \mathrm{P9})$, pois a equipe gestora incentiva a autonomia profissional, favorecendo o diálogo e a resolução conjunta de problemas: "Todos os locais em que eu trabalho têm um gestor. [...] é uma equipe. Todos falam a mesma língua. Todos atuam da mesma forma" (P2), ou então, "[...] a relação com os gestores permite sanar as dificuldades, tanto no momento de trabalho e, às vezes, até no pessoal. [...] Estão sempre dispostos a ajudar a melhorar" (P5).

De outro modo, a insatisfação apontada por alguns investigados (P3, P6, P8, P10) é decorrente de divergências com os gestores, nomeadamente a falta de aproximação e comunicação efetiva e a pouca valorização profissional. P3 comenta que "[...] nos locais que eu trabalho, nós não temos este contato direto com o gestor. [...] A gente gostaria de ter uma aproximação maior, para que pudéssemos relatar nossas dificuldades", ao passo que P10 relata que a gestão "[...] deixa muito a desejar, eles muitas vezes te cobram uma coisa, mas quando você consegue fazer acontecer, eles não te valorizam por isso" (P10).

Embora seja possível notar inúmeros desafios ao longo da carreira profissional em Educação Física, parecem existir determinados motivos que impulsionam a sua atuação. A abertura ao diálogo com os gestores, o relacionamento transparente, a autonomia e o respeito e a possibilidade de participação efetiva, seja na elaboração da metodologia de trabalho, seja nas demais decisões inerentes à dinâmica do ambiente de atuação, estão entre os fatores que contribuem para a percepção de qualidade no espaço de trabalho desses profissionais (Nogueira, 2006).

Quanto ao relacionamento com os pares e/ ou demais funcionários, os profissionais (P3, P4, P7, P9) demonstraram satisfação, destacando as conexões positivas que estabelecem no local de trabalho. De acordo com P3, não há "[...] dificuldades nas relações interpessoais com os colegas. [...] Sempre temos que buscar ser um mediador com os outros funcionários também". De fato, a satisfação com a profissão expressada por aqueles que atuam em academias de ginástica é proporcionada, sobretudo, pelo ambiente agradável de trabalho e pelos relacionamentos interpessoais estabelecidos (Freitas et al., 2014).

Neste estudo, particularmente, as relações interpessoais com os alunos foram indicadas por alguns profissionais (P2, P3, P8) como aspectos que impactam a insatisfação profissional, principalmente pela falta de pontualidade e compromisso por parte dos alunos em relação ao horário das aulas:

O que eu acho que mais pega nessa questão de cumprir horário é que, se o seu aluno atrasar 15, 20 minutos, você é obrigada a se virar para atender mais 15, 20 minutos após o horário dele. $O$ que não deve ser feito. (P3). 


\section{TRABALHO E ESPAÇO TOTAL DE VIDA}

Uma parcela considerável dos profissionais mencionou as implicações do trabalho na vida pessoal e social (P1, P2, P3, P4, P5, P6, P7, P8, P10), e outra, a prática regular de atividades físicas ( $\mathrm{P} 2, \mathrm{P} 8, \mathrm{P} 9, \mathrm{P} 10)$, como aspectos que impactam a satisfação e a insatisfação com a profissão. Especificamente, na relação entre o trabalho e a vida pessoal e social, a maioria se demonstrou satisfeita (P2, P3, P4, P5, P6, P7), pois consegue conciliar o tempo de permanência no ambiente de trabalho e o tempo destinado às atividades particulares. Entretanto, há um consenso de que a possibilidade de conciliação entre essas áreas foi adquirida e diretamente influenciada pela necessidade e decisão pessoal em abdicar de algumas oportunidades laborais para dispor de tempo e qualidade nas esferas pessoal e social da vida:

\begin{abstract}
Hoje eu tento largar mão de muitos trabalhos, eu tenho que falar não, sair de lugares que eu trabalhava antes, para conseguir ter um tempo pra mim, pra minha família, pra minha casa, pra eu não enlouquecer, porque isso vai desmotivando. (P2).
\end{abstract}

Consigo tranquilamente conciliar os dois. Quando me formei, trabalhava à noite e nos finais de semana, então, não conseguia ver minha família direito. Porém, quando fui ingressando no mercado de trabalho, consegui fazer uma carga horária que conciliasse com a minha vida pessoal. (P3).

Alguns dos profissionais investigados (P1, P8, P10) mostraram-se insatisfeitos com a profissão por causa da falta de tempo para outras atividades pessoais, ocasionada pela elevada carga horária:

Se você for ver, não tem tempo para o lazer, você chega cansado em casa [...]. Aí você vai jantar, vai tomar banho, e se for fazer algum lazer, você vai dormir às 2 da manhã, e precisa acordar no outro dia às $6 \mathrm{da}$ manhã. (P8).

A insatisfação com a profissão também foi associada à falta de tempo e às condições estruturais para a prática regular de atividades físicas (P2, P8, P9, P10). De acordo com o P2, a

[...] atividade física regular é a maior complicação para nós da área da Educação Física, porque a gente passa o dia inteiro dentro de uma academia. Quando a gente vai embora, [...] tem que treinar. E a gente não aguenta mais ficar dentro de uma academia,

e para $\mathrm{P} 8$, " [...] me exercito na aula, mas, tempo para fazer atividade física, não tenho".

Nessa perspectiva, é possível observar a relação entre lazer/atividade física e a carga horária de trabalho. Quanto maior a carga horária, menor o tempo destinado ao lazer/atividade física. Assim, torna-se cada vez mais comum que os profissionais da área atuem na prevenção da saúde dos alunos/clientes, descuidando-se da própria para elevar os rendimentos salariais (Espírito-Santo e Mourão, 2006; Mendes e Azevêdo, 2014). Acerca disso, Guimarães et al. (2011) verificaram que a maior parte dos profissionais que atua em mega-academias possui, em média, duas horas de atividades de lazer ou atividade física semanais. Esses fatores, portanto, podem contribuir para o surgimento de problemas de saúde (Guimarães et al., 2011; Silva e Lüdorf, 2012) e influenciar na percepção de insatisfação com o trabalho.

\section{RELEVÂNCIA SOCIAL DA VIDA NO TRABALHO}

Em relação à relevância social da função que desempenham, todos os participantes (P1, P2, P3, P4, P5, P6, P7, P8, P9, P10) mostraram-se insatisfeitos. Dentre os principais motivos citados, destaca-se a pouca valorização por parte dos alunos e gestores nos locais de trabalho e a falta de reconhecimento da sociedade em geral:

Nós nos especializamos, fazemos curso, aí aplico o que conheci [...] e tanto faz para os alunos. É difícil para os alunos verem, acredito que isso entra mais em uma questão social, os gestores também não veem isso. (P6).

[...] nós somos da área da saúde e não somos valorizados como profissionais da área da saúde, por não atuarmos na causa, não tratar o problema. [...] Então, por conta de a gente trabalhar com a prevenção, eu acredito que as pessoas acabam não valorizando isso. [...] Então, isso é complicado, porque as pessoas acreditam que o profissional de Educação Física é um mero instrutor ali para falar qual é o aparelho que ela deve usar. (P2).

Parece que, embora o processo de profissionalização da Educação Física tenha desencadeado discussões e expectativas para o desenvolvimento em diferentes frentes, principalmente nos âmbitos social e econômico, ainda se verifica o impacto reduzido dessas ações na legitimidade social e nas condições de trabalho diante de outras profissões. Nessa conjuntura, a baixa remuneração e a falta de prestígio social podem estar relacionadas ao fato de que muitos serviços oferecidos pelos profissionais da área, em ambiente informal, ainda são praticamente inacessíveis a uma parcela significativa da sociedade, já que se restringem a espaços privados.

De outro modo, as atividades dos professores que atuam em ambientes formais carregam valores inerentes à profissão docente, estando legitimadas nas instituições de ensino (Fonseca e Souza, 2020). Isso pode justificar, sobretudo, os níveis mais altos de satisfação na relevância social do trabalho atribuídos pelos professores de Educação Física que atuam na Educação Básica (Both, 2011; Farias et al., 2015; Nascimento et al., 2019) quando comparados aos profissionais que atuam em academias de ginástica (Krug et al., 2009; Mendes e Azevêdo, 2014; Nogueira, 2006). 


\section{OPORTUNIDADE DE PROGRESSÃO NA CARREIRA}

Nessa categoria, alguns dos profissionais investigados demonstraram satisfação (P3, P4, P8 e P9) e apresentaram boas expectativas para o crescimento em seu espaço de atuação e para os demais profissionais da área. Destacam-se as seguintes falas:

Minhas expectativas atualmente são crescer na profissão, criar meu nome, levar um trabalho de qualidade e que possa fazer a diferença na vida das pessoas. [...] Com este tipo de atitude, acredito que estamos construindo uma classe de profissionais bem remunerados e capacitados, e que lutem pelo seu espaço com qualidade no mercado de trabalho. (P3).

As minhas perspectivas são as melhores possiveis, $e$ a velocidade com que isso vai acontecer vai depender exclusivamente da gente. [...] A minha perspectiva é estar em um nível alto, eu quero chegar, não cheguei lá, [...] mas estou trabalhando pra isso. (P9).

Apenas um dos pesquisados (P2) indicou estar insatisfeito com as oportunidades de desenvolvimento profissional, em virtude da baixa remuneração, da elevada carga horária e do número de locais onde atua:

Se a remuneração fosse legal talvez [...] teria mais tempo para investir na carreira, fazer curso. É isso que complica, porque você acaba tendo que trabalhar os três turnos sem parar. E isso acaba deixando o profissional sem vontade de buscar conhecimentos.

As perspectivas positivas indicadas pelos profissionais podem estar ligadas à expansão do setor, devido a mudanças ocorridas nos hábitos de vida e saúde da sociedade ao longo dos anos (Mendes e Azevêdo, 2014). Além disso, alguns participantes do estudo relataram ter boas expectativas acerca da área de personal trainer ou de treinamentos personalizados, pois se trata de um mercado que tem se tornado um atrativo para os profissionais de Educação Física em função da remuneração relativamente mais alta quando comparada às demais atividades desenvolvidas no contexto informal (Guimarães et al., 2011).

A satisfação com as oportunidades futuras na carreira também pode estar relacionada ao fato de os participantes do estudo serem mais jovens, uma vez que o mercado das academias e os próprios clientes buscam selecionar profissionais com perfil estético "jovem e atlético", na expectativa de que o trabalho seja mais qualificado. Com o avanço da idade e da carreira, é comum que os profissionais desse segmento se sintam mais insatisfeitos e se voltem a outros espaços, como projetos sociais, clubes e, eventualmente, escolas (Freitas et al., 2014; Lüdorf e Ortega, 2013).

\section{CONCLUSÕES}

A partir dos depoimentos apresentados pelos profissionais que atuam em academias de ginástica é possível concluir que há uma relação direta entre as condições objetivas de trabalho e a satisfação e insatisfação com o desempenho profissional. A realidade vivida por esses profissionais reflete na insatisfação com a remuneração, com as condições de trabalho, com a relevância social do trabalho e com a possibilidade de articulação entre o trabalho e o espaço total de vida. A satisfação com as relações interpessoais e a integração no trabalho, além da expectativa com as oportunidades de progressão na carreira, são aspectos que parecem contribuir para a permanência deles nesse espaço de atuação.

Convém observar que o aspecto limitante desta investigação compreende o diagnóstico de uma realidade específica. É importante salientar ainda a escassez de estudos na área da Educação Física que buscam analisar a satisfação no trabalho de profissionais que atuam no espaço informal. Esses aspectos, portanto, impactaram na comparação dos resultados encontrados com os de estudos de natureza similar. A sugestão, portanto, é a ampliação de estudos qualitativos dessa natureza no sentido de aprofundar a compreensão sobre a realidade laboral dos profissionais de Educação Física inseridos em academias de ginástica.

\section{FINANCIAMENTO}

O presente trabalho não contou com apoio financeiro de nenhuma natureza para sua realização.

\section{CONFLITOS DE INTERESSE}

As autoras declaram não haver conflitos de interesse.

\section{REFERÊNCIAS}

Antunes MFC, Lüdorf SMA, Coelho CAA Fo. O trabalho do profissional de Educação Física com ginástica coletiva em academia. Educ Foco. 2017;22(1):223-48. http://dx.doi. org/10.22195/2447-524620172219619.

Bardin L. Análise de conteúdo. Lisboa: Edições 70; 2016.

Both J, do Nascimento JV, Sonoo CN, Lemos CAF, Borgatto AF. Bem-estar do trabalhador docente de educação física do sul do Brasil. Rev Bras Ciênc Esporte. 2017;39(4):380-8. http://dx.doi.org/10.1016/j.rbce.2016.01.002.

Both J. Bem estar do trabalhador docente em Educação Física da região sul do Brasil [tese]. Florianópolis: Universidade Federal de Santa Catarina; 2011.

Broch C. Trabalho docente em Educação Física na Educação Superior: configuração e satisfação profissional [tese]. Maringá: Universidade Estadual de Maringá; 2018.

Espírito-Santo G, Mourão L. A auto-representação da saúde dos professores de educação física de academias. Rev Bras Ciênc Esporte. 2006;27(3):39-55.

Farias GO, Both J, Folle A, Pinto MG, Nascimento JV. Satisfação no trabalho de professores de Educação Física do magistério público municipal de Porto Alegre. Rev Bras Ciên Mov. 2015;23(3):5-13. http://dx.doi.org/10.18511/01031716/rbcm.v23n3p5-13.

Fonseca RG, Souza S No. Educação Física, profissionalização e mercado de trabalho: uma análise sobre o projeto 
profissional. Movimento. 2020;26:e26024. http://dx.doi. org/10.22456/1982-8918.98699.

Freitas DC, Palma A, Coelho CDA Fo, Lüdorf SMA. O envelhecer na visão do profissional de Educação Física atuante em academia de ginástica: corpo e profissão. Movimento. 2014;20(4):1523-41. http://dx.doi.org/10.22456/19828918.46094.

Furtado RP, Santiago LP. Educação Física e trabalho: considerações a respeito da inserção profissional de egressos da FEF-UFG. Rev Bras Educ Fís Esporte. 2015;29(2):325-36. http://dx.doi.org/10.1590/180755092015000200325.

Gil AC. Como elaborar projetos de pesquisa. 6. ed. São Paulo: Atlas; 2017.

Guimarães JCM Fo, Moura DL, Antunes MM. Quando a beleza põe a mesa: uma análise das condições de trabalho do profissional de educação física em mega-academias. Motrivivência. 2011;23(36):197-213. http://dx.doi. org/10.5007/2175-8042.2011v23n36p197.

Krug RR, Damásio W, Conceição VJS, Krug HN. Perfil dos profissionais de Educação Física que atuam em academias de musculação na região central da cidade de Criciúma-SC. Bol Bras Ed Fís. 2009;83:1-9.

Lazzarotti A Fo, Silva AM, Nascimento JV, Mascarenhas F. Modus operandi da produção científica da EF: uma análise das revistas e suas veiculações. J Phys Educ. 2012;23(1):114. http://dx.doi.org/10.4025/reveducfis.v23i1.12551.

Lüdorf SMA, Ortega FJG. Marcas no corpo, cansaço e experiência: nuances do envelhecer como professor de Educação Física. Interface. 2013;17(46):661-75. http:// dx.doi.org/10.1590/S1414-32832013005000019.
Mendes AD, Azevêdo PH. O trabalho e a saúde do educador físico em academias: uma contradição no cerne da profissão. Rev Bras Educ Fís Esporte. 2014;28(4):599-615. http://dx.doi.org/10.1590/1807-55092014000400599.

Nascimento RK, Martins AC, Both J, Farias GO, Guimarães JRS, Folle A. Satisfação no trabalho de docentes de educação física: uma revisão sistemática. Movimento. 2019;25:e25004. http://dx.doi.org/10.22456/19828918.82573.

Nogueira L. Qualidade de vida no trabalho do professor de educação [tese]. Rio de Janeiro: Universidade Gama Filho; 2006.

Palma A, Jardim S, Luiz RR, Silva J Fo. Trabalho e saúde: o caso dos professores de educação física que atuam em academias de ginástica. Cad IPUB/UFRJ. 2007;13:11-30.

Proni MW. Universidade, profissão Educação Física e o mercado de trabalho. Motriz. 2010;16(3):788-98. http://dx.doi. org/10.5016/1980-6574.2010v16n3p788.

Silva AC, Lüdorf SMA. Possíveis relações entre corpo, saúde eo envelhecimento do professor de Educação Física. Movimento. 2012;18(2):187-204. http://dx.doi. org/10.22456/1982-8918.18807.

Silva R, Andrade A, Zanelli JC. O discurso real e o discurso ideal de professores de Educação Física do ensino superior sobre docência. Movimento. 2010;16(3):131-52. http://dx.doi. org/10.22456/1982-8918.10772.

Verenguer RCG. Intervenção profissional em Educação Física: expertise, credencialismo e autonomia. Motriz. 2004;10(2):123-34.

Walton RE. Quality of working life: what is it. Sloan Manage Rev. 1973;15(1):11-21. http://dx.doi.org/10.12691/ education-4-20-3. 